\title{
A relação da tecnologia com o processo de recrutamento e seleção de pessoal a partir da visão de gestores de três hotéis de João Pessoa, Paraíba/PB, Brasil
}

\section{The relationship of technology with the process of recruiting and selecting people by the managers' point of view from three hotels in João Pessoa, Paraíba/PB, Brazil}

\author{
Suênia Soares Santos (SANTOS, S. S.) ${ }^{*}$ e \\ Thales Batista de Lima (LIMA, T. B.)
}

\begin{abstract}
RESUMO - A pesquisa objetivou compreender a relação do uso da tecnologia com o processo de recrutamento e seleção de pessoal a partir da visão de três gestores de hotéis da orla de João Pessoa/Paraíba, Brasil. No estudo se utilizou uma abordagem qualitativa, método dedutivo e descritivo. Além disso, realizou-se uma entrevista estruturada em três hotéis da orla pessoense com gestores de Recursos Humanos que atuavam no recrutamento e seleção de pessoal para maior compreensão da pesquisa. Quanto à análise, balizou-se pela análise compreensiva e interpretativa dos dados. Os resultados mostraram que a tecnologia estava presente nos hotéis, sendo necessário que houvesse uma adaptação a ela. Na percepção dos gestores entrevistados os impactos tecnológicos resultaram diversas mudanças no recrutamento e seleção dos hotéis como rapidez na tomada de decisões e flexibilidade, tornando os processos mais ágeis e dinâmicos para se manter atualizados na busca de profissionais qualificados. Portanto, concluiu-se que a tecnologia foi essencial para gestores hoteleiros e candidatos, uma vez que desempenha um papel preponderante nas operações dos hotéis. E a utilização das ferramentas tecnológicas foi visto como um desafio para os gestores que precisam de uma nova adaptação no que tange a esta política de recrutamento e seleção.
\end{abstract}

Palavras-chave: Turismo; Recrutamento; Seleção; Tecnologia.

ABSTRACT - The objective of this research was to understand the relationship between the use of technology and the recruitment and selection of people, based on the view of three hotel managers from João Pessoa Coast, Paraíba, Brazil. The study used a qualitative, deductive and descriptive approach. In addition to it, a structured interview was conducted in three hotels from the coast of João Pessoa with Human Resources managers who worked in the recruitment and selection of people for a better understanding of the research. As for the analysis, it was based on a comprehensive and interpretative analysis of the data. The results showed that the technology was present in the hotels and it was necessary to adapt to it. In the perception of the managers interviewed the technological impacts resulted in several changes in the recruitment and selection of the hotel as speed in decision making and flexibility, making the processes

\footnotetext{
* Formação: Bacharelado em Hotelaria pela Universidade Federal da Paraíba. Gestora hoteleira em uma rede de hotéis. Endereço físico para correspondência: Rua Dois, 236, ap. 3, bairro Manguinhos. CEP: 21046-630 - Rio de Janeiro/RJ - Brasil. E-mail: sueniasoaressantos@ gmail.com

** Formação: Graduação em Administração pela Universidade Federal da Paraíba. Mestrado em Administração pela Universidade Federal da Paraíba. Doutorado em Administração pela Universidade Federal da Paraíba. Docente do Departamento de Ciências Sociais Aplicadas/UFPB. Endereço físico para correspondência: Rua Cantora Maria da Glória Gouveia de Vasconcelos, 49, bairro Bessa. CEP: 58037 313 - João Pessoa/PB - Brasil. E-mail: thalesufpb@gmail.com
} 
more agile and dynamic to stay updated in the search for qualified professionals. Therefore, it was concluded that the technology was essential for hotel managers and candidates, since it plays a preponderant role in hotel operations. And the use of technological tools was seen as a challenge for managers who need a new adaptation regarding this policy of recruitment and selection.

Key words: Tourism; Recruitment; Selection; Technology. 


\section{INTRODUÇÃO}

Os gestores das redes de hotéis estão sempre inovando com o avanço da tecnologia, assim, no recrutamento buscam atrair pessoas capacitadas que tenham potencial para trabalhar dentro dos hotéis, e quanto a seleção de pessoas é uma fase bem importante por selecionar e avaliar cada candidato que estiver apto ou não para trabalhar desenvolvendo atividades com dedicação e qualidade dentro das instituições hoteleiras. Isso faz com que as instituições sejam diferenciadas das concorrentes por trabalharem com profissionais capacitados que buscam crescer junto com as organizações hoteleiras.

Para Godinho (2008), o ferramental tecnológico torna possível captar, triar, avaliar e contratar o profissional mais adequado ao preenchimento da vaga de forma eficiente e eficaz, minimizando o tempo de preparação e execução do processo seletivo, além de custos e mão-de-obra. Nesse sentido, esses profissionais precisam estar preparados para recrutar e selecionar pessoas que possam contribuir com o desenvolvimento da empresa, por isso os meios pelos quais são utilizados para desenvolver tal função necessita estar adequado, requerendo tecnologias que tragam maior agilidade e confiabilidade no processo de escolha de profissionais.

A tecnologia está cada vez mais presente no cotidiano das pessoas, tanto na vida pessoal como na profissional, agregando utilidade e necessidade de informações precisas para alcançar resultados com maior abrangência. Segundo Ferreira e Vargas (2014), a internet faz parte da rotina da maioria das empresas sendo utilizada para auxiliar no processo produtivo, mas também em outras atividades como recrutamento e seleção de novos funcionários, sendo estes a base da excelência empresarial.

Assim, novas tecnologias estão sendo utilizadas nos departamentos de Recursos Humanos dos empreendimentos, nas empresas que têm especialidade em inovar talentos, nas implantações dos processos de selecionar e recrutar o pessoal. Com a agilidade e a eficácia na priorização de contratar pessoas, funcionam de tal forma que obtém veracidade na execução e qualificação que se utiliza nos níveis de competitividade dentro da organização.

Salienta-se que o entendimento por tecnologias relacionadas com o processo de recrutamento e seleção se refere ao potencial do ambiente virtual, explorando a internet como um facilitador para a execução de fases tanto do recrutamento como da seleção de 
pessoal (LIMA, AMARAL, 2018). A relevância da compreensão do uso da tecnologia na política de recrutamento e seleção é reforçada por Abreu et al. (2014) ao evidenciarem que hotéis ainda desconhecem o valor da tecnologia como forma de contribuir no processo seletivo, uma vez que a subutilizam por acreditarem que requer bastante investimento financeiro. No entanto, Gomes, Scherer e Lobler (2012) destacam que o uso, por exemplo, de redes sociais nesta política não gera custos, facilita o contato com o público jovem, auxilia no fornecimento de banco de dados para contato e possibilita um complemento da imagem da pessoa.

Nada obstante, vale a pena enfatizar que as redes hoteleiras cada vez mais se alinham às novas demandas de mercado com relação a sua clientela, na qual há nichos de mercado no ramo hoteleiro voltados aos negócios e eventos corporativos, também hotéis que se especializam em atrações para um contexto familiar, de atividades de lazer, bem como há outros voltados a grupos específicos, por exemplo, somente casais ou investimentos para o público jovem ou da terceira idade. Enfim, percebe-se que tal especialização requer profissionais mais habilitados para se relacionar e atender esses diferentes grupos de hóspedes, que estão mais exigentes.

Por isso, os gestores dos próprios hotéis têm se preocupado com o perfil de seus funcionários para que sejam capazes de se adequarem melhor ao próprio perfil tido de cliente. $\mathrm{E}$ as tecnologias podem ajudar em encontrar onde quer que seja este perfil mais apropriado às necessidades dos hotéis. Isso pode ser reforçado por estudos de Píccolo e Gândara (2012) que evidenciaram o crescente turismo de negócios na capital paranaense, e o de Silva (2017) que aponta o interesse do poder público em investimentos turísticos no Pará como forma de atrair turistas e promover o desenvolvimento econômico na região. Assim, exigem-se do setor hoteleiro funcionários capazes de atender bem, sendo hospitaleiros com os perfis distintos de hóspedes.

Sendo assim, a inovação tecnológica a partir de procedimentos baseados em testes online, vídeo currículo e vídeo entrevista, está sendo cada vez mais implantada pelos departamentos de Recursos Humanos, a qual pode contribuir por recrutar profissionais mais qualificados e adequados com o perfil da empresa. Desse modo, nesta pesquisa se objetivou compreender a relação do uso da tecnologia com o processo 
de recrutamento e seleção de pessoal a partir da visão de três gestores de hotéis da orla de João Pessoa, Paraíba, Brasil.

\section{FUNDAMENTAÇÃO TEÓRICA}

Recrutamento e a seleção de pessoas compõem um processo que está direcionado a área de recursos humanos, onde há uma escolha de candidatos para assumir determinadas vagas dentro de uma empresa. Para Milkovich e Boudreau (2000), recrutamento é um processo de identificação e atração de um grupo de candidatos, dos quais alguns serão escolhidos e contratados pela empresa. Para Limongi França e Arellano (2002), a seleção é a escolha dos candidatos mais adequada para organização, dentre os candidatos recrutados, por meio de vários instrumentos de análise avaliação e comparação de dados.

O recrutamento e a seleção são umas das mais importantes ferramentas de gestão de pessoas em uma empresa. Ferreira e Vargas (2014) alegam que os procedimentos de recrutamento e seleção visam esquadrinhar no mercado de trabalho os profissionais que se encaixam melhor ao perfil demandado pela vaga a ser ocupada na empresa.

Segundo Fernandes (2011) o recrutamento é feito a partir das necessidades de recursos humanos na organização e se divide em três etapas: pesquisa interna das necessidades, pesquisa interna do mercado e a definição das técnicas de recrutar a utilizar formando o planejamento de recrutamento.

A seleção integra o processo de agregar valor, que funciona após a escolha das técnicas de recrutamento que melhor atendam às necessidades organizacionais, buscando escolher o profissional que melhor atenda as necessidades do cargo e as expectativas da organização (FERNANDES, 2011). Já Silva (2015) comenta que é fundamental que se tenha uma clara definição das características do cargo, pois a seleção é feita justamente com o objetivo de preencher uma vaga que irá ocupar este cargo e desempenhar suas funções.

É importante apontar que o processo de recrutamento não deve se destinar apenas a coletar currículos de candidatos para a ocupação de uma determinada vaga, mas também deve se preocupar em divulgar a empresa e torná-la atraente para os 
diversos candidatos (MONTENEGRO, 2012).

$\mathrm{O}$ recrutamento e seleção online são uma maneira de atrair candidatos sem ter um alto custo. Com o passar dos anos a internet vêm tomando espaço dentro das organizações, criando um canal de contato com candidatos, facilitando o recrutamento de novos talentos.

De acordo com Rodrigues et al. (2014) os avanços tecnológicos têm agregado para a área de Recursos Humanos, pois a utilização de determinadas tecnologias facilita e agiliza o gerenciamento de informações, reduz custos e gera maior precisão na escolha do candidato, beneficiando a própria organização com acertos nos perfis profissionais condizentes com a identidade organizacional. Os mesmos autores acrescentam que os processos de recrutamento e seleção estão sendo melhorados, e as empresas estão adotando métodos tecnológicos para esses processos, nos quais a internet é um grande instrumento para esses processos de recrutar e selecionar de forma diferenciada.

$\mathrm{O}$ recrutamento constitui atividade das mais importantes em recursos humanos e uma ferramenta que está sendo cada vez mais utilizada é o recrutamento online, já que consegue agregar uma quantidade grande de informações e reduz o tempo na seleção das mesmas (FERREIRA; VARGAS, 2014).

A internet vem atraindo novos candidatos para recrutamentos em hotéis sem ter custos muitos altos, possibilitando ao gestor de um estabelecimento hoteleiro o funcionário que ele deseja. Para Mendes Filho e Ramos (2002), a Internet é vista como uma das tecnologias de informação mais importantes na atualidade, tendo na indústria hoteleira um grande usuário, que a utiliza para disponibilizar vários serviços.

O autor diz ainda que a tecnologia desempenhará cada vez mais um papel de maior importância nas operações dos hotéis no futuro e deve ser uma parte integral das atividades hoteleiras. Rodrigues et al. (2014) alegam que o uso da internet aumenta o desempenho da organização no processo de seleção via internet, onde se pode realizar entrevistas e diversos testes online sem a necessidade inicial de deslocamento dos candidatos.

Ainda comenta que essas facilidades atendem as necessidades do setor hoteleiro que, a cada dia mais está se profissionalizando na busca por soluções que viabilizem a prestação de serviços com excelência. 


\section{METODOLOGIA}

Esta pesquisa caracteriza-se como uma abordagem qualitativa, em que segundo Godoy (1995, p. 21) "o pesquisador vai a campo buscando captar o fenômeno em estudo a partir da perspectiva das pessoas nele envolvidas, considerando todos os pontos de vista relevantes." Quanto ao método é visto como dedutivo, que de acordo com Gil (2008) parte de princípios reconhecidos como verdadeiros e indiscutíveis e possibilita chegar a conclusões de maneira puramente formal, isto é, em virtude unicamente de sua lógica.

Também este estudo pode ser considerado descritivo e de natureza aplicada, pois objetivou gerar conhecimentos para aplicação prática, dirigidos à solução de problemas específicos, envolvendo interesses locais, como assinalam Gerhardt e Silveira (2009).

Os sujeitos da pesquisa são constituídos por três gestores de Recursos Humanos que estavam atuando em três hotéis localizados na orla de João pessoa-PB. Tais hotéis foram selecionados pelos critérios de adoção de algum ferramental tecnológico, porte, atuação na principal área turística da cidade (a orla marítima) e a facilidade de acesso. A seguir, apresenta-se o perfil dos mesmos (QUADRO 1), destacando que estão representados pelas letras "GRH” (Gestor de Recursos Humanos) e depois por um número que os identificam, do qual segue sequencialmente do "GRH1" até "GRH3".

QUADRO 1 - PERFIL DOS ENTREVISTADOS

\begin{tabular}{|c|c|c|c|c|c|}
\hline Gestor de RH & Gênero & Faixa etária & Escolaridade & $\begin{array}{c}\text { Tempo no } \\
\text { hotel }\end{array}$ & $\begin{array}{c}\text { Tempo atual } \\
\text { no cargo }\end{array}$ \\
\hline GRH1 & Masculino & Até 30 anos & $\begin{array}{c}\text { Superior } \\
\text { Incompleto }\end{array}$ & 6 meses & 6 meses \\
\hline GRH2 & Masculino & Entre 31 e 45 & $\begin{array}{c}\text { Superior } \\
\text { Completo }\end{array}$ & 10 anos & 6 anos \\
\hline GRH3 & Feminino & Até 30 anos & $\begin{array}{c}\text { Superior } \\
\text { Completo }\end{array}$ & 5 anos & 5 anos \\
\hline
\end{tabular}

FONTE: Elaboração própria (2018).

O método de coleta de dados foi executado a partir de uma entrevista estruturada, tipo de coleta que segundo Gil (2002, p. 117) "se desenvolve a partir de relação fixa de perguntas". Assim, as questões foram direcionadas ao conhecimento dos gestores sobre tecnologias como forma de auxiliar o processo de recrutamento e seleção, como eles avaliavam o seu uso, a eficácia desde a divulgação até uma contratação pelo ambiente virtual. Além disso, que apontassem fatores que a tecnologia 
poderia aperfeiçoar no processo seletivo e as limitações enfrentadas. Doravante, as entrevistas foram marcadas por $e$-mail e ligação telefônica. Tiveram duração média de 20 minutos, além de terem sido gravadas e transcritas.

Para se ter uma melhor compreensão do impacto do uso da tecnologia nos hotéis da orla paraibana, foi utilizada a análise interpretativa e compreensiva dos dados (SILVA, 2005). Sendo assim, a análise desde trabalho seguiu os passos de Silva (2005) na direção da compreensão do fenômeno que foram: a transcrição na integra das entrevistas e a criação de protocolos de codificação a partir da leitura das entrevistas.

Após a leitura do texto transcrito das entrevistas os entrevistados foram codificados e divididos em categorias, emergidas das questões das entrevistas, que visaram atender ao objetivo da pesquisa, cujas categorias foram: Meios Tecnológicos utilizados; Perfil adequado do candidato; Divulgação de vagas; O impacto tecnológico no mercado; Contribuição dos aparatos tecnológicos; Limitações dos aparatos tecnológicos no processo de recrutamento e seleção; e, Contribuição de tecnologia no recrutamento e seleção do Hotel.

\section{DISCUSSÃO E REFLEXÃO DOS RESULTADOS}

Neste tópico se discorre a respeito das reflexões acerca das categorias emergidas durante as entrevistas realizadas, no qual trechos das falas são evidenciados para discussão balizada por meio das ideias dos autores utilizados no trabalho no sentido de compreender melhor essa relação entre tecnologia e os processos de recrutamento e seleção de pessoal praticados pelos gestores dos hotéis pesquisados.

\subsection{MEIOS TECNOLÓGICOS UTILIZADOS}

Os meios tecnológicos vêm garantindo mais rapidez e agilidade no processo de recrutamento e seleção. Segundo Araújo e Ramos (2002) as organizações estão apostando na Internet para recrutar talentos e reduzir os custos dos seus onerosos processos de provisão de pessoas, ao mesmo tempo em que aumentam os horizontes do recrutamento e facilitam a vida dos candidatos. Mas nem sempre as empresas estão 
preparadas para receber tais inovações e acompanhar o desenvolvimento da tecnologia. Sendo assim quando foram indagados sobre os meios tecnológicos utilizados foi afirmado que:

\footnotetext{
As tecnologias usadas para o recrutamento é apenas a divulgação em nossos sites, como a opção de envio de currículo, todos enviados ou entregues na recepção são entregues a diretoria e governança, assim são analisados (GRH.1).
}

O entrevistado GRH.3 falou também que seus meios tecnológicos ocorriam só através de sites como comentou a seguir: " Processo seletivo divulgado em site."

É importante ressaltar como eles avaliaram o uso das ferramentas tecnológicas nas suas técnicas de seleção conforme segue a fala: " Sobre a avaliação das ferramentas utilizadas, sentimos a necessidade de uma ferramenta ou auxílio para realizar a seleção e a avaliação" (GRH.1).

O GRH.2 relatou em seu comentário que as ferramentas tecnológicas tinham importância porque tornavam seus processos mais precisos e confiáveis como se pode observar a seguir: "Fundamentais. Pois além de dinamizarem, tornam os processos mais precisos e confiáveis".

Martins (2015) reforça ainda que as ferramentas que as novas tecnologias proporcionam facilitam a comunicação e posterior realização de um trabalho mais eficiente através da aproximação virtual de empregadores e candidatos.

Mas percebeu-se nas respostas dos entrevistados sobre os meios tecnológicos utilizados que ainda estavam sendo uma barreira, pois mostrava que mesmo utilizando sites, o presencial ainda tinha uma maior relevância na contratação dos candidatos. Embora o trabalho virtual fosse perfeitamente viável, os entrevistados mencionaram preferir estar no mesmo ambiente que os candidatos, observando as expressões físicas e corporais para a contratação.

\subsection{PERFIL ADEQUADO DO CANDIDATO}

Para se contratar é necessário uma série de cuidados para encontrar o perfil adequado do candidato, aquele que se ajuste melhor a vaga. De acordo com Lemes e 
Weschenfelder (2015) em seus perfis virtuais, os candidatos expõem suas opiniões, valores, preconceitos e traços de suas personalidades.

Os gestores explicaram que consideravam necessária uma avaliação presencial para indicar o perfil adequado do candidato, pois na maioria das vezes se fazia fundamental ter uma consulta do que foi informado no envio para obter a certeza no momento da efetivação da contratação. A ênfase é apresentada nos trechos a seguir:

\footnotetext{
Não, é necessário a avaliação presencial para o conhecimento e consulta do que foi informado no envio. Assim, podemos ter certeza e confiança do que estamos contratando (GRH.1).

Não. Os meios virtuais servem como filtros, pois no ramo de atendimento direto ao público, há pontos do processo seletivo que só podem ser avaliados pessoalmente (GRH.2).

Pode identificar, porém não tem a certeza que irá ser como demonstra, a entrevista em presença do candidato já percebemos a vontade e empolgação do selecionado. Entrevistar sem ver bem a expressão e o gesto se torna vago (GRH.3).
}

Portanto os gestores GRH.1, GRH.2 e GRH.3 tiveram os mesmos pontos de vista para escolher o perfil adequado de seus candidatos, que mesmo com o uso da tecnologia, o presencial ainda era essencial para contratação.

Gontijo (2005) menciona que esse processo de seleção é essencial para o sucesso de uma empresa, pois é por meio dele que as organizações podem identificar talentos com potencial para fazer a diferença neste mercado tão competitivo.

\subsection{DIVULGAÇÃO DE VAGAS}

A divulgação das vagas é salutar para a empresa, uma vez que Silva, Ferrett e Mancini (2015) alegam que o recrutamento é de suma importância na organização, pois não se trata apenas de uma mera divulgação, mas sim de chamar a atenção de profissionais qualificados, para o preenchimento da necessidade da empresa.

Sendo assim, quando questionados como o hotel utilizava a tecnologia na política de divulgação um dos entrevistados relatou que: "Dependendo da vaga em questão, divulgamos em Redes Sociais Profissionais (Ex. Linkedin), Agências Virtuais (Catho, Vagas.com, Infojobs) ou em Fóruns de Hotelaria” (GRH.2). 
Em contrapartida o entrevistado (GRH.1) disse que o único meio de divulgação ainda era por site e e-mail como afirmou a seguir:

Como informado, o nosso único meio de tecnologia para o recrutamento é o envio pelo site ou e-mail. Não temos um contato ou uma forma de divulgação direta para esta vaga. Então não conseguimos abranger a demanda de procura ao setor.

Percebeu-se que cada gestor entrevistado tinha sua própria política de divulgação de vagas, disponibilizando dos recursos que se tinha dentro do hotel. A divulgação das vagas pode oferecer muitos benefícios para uma empresa, trazendo vantagens de atingir um público maior de possíveis candidatos.

\subsection{O IMPACTO TECNOLÓGICO NO MERCADO}

Os avanços tecnológicos trazem grande impacto no mercado de trabalho, trazendo mudanças na área de recursos humanos, tornando mais rápidas as tomadas de decisões para a empresa. Para Pontes (2010) quanto maior for a velocidade dos avanços tecnológicos, maior a necessidade de mudanças nas próprias empresas que criaram tais avanços tecnológicos, e o processo de inovação contínua, de forma cada vez mais acelerada. A empresa que não dispõe de flexibilidade para atualização se torna ameaçada pelo mercado devido a sua estagnação frente a ambientes dinâmicos.

Foi perguntado aos gestores de que maneira eles enxergavam o impacto da tecnologia no mercado no processo de recrutamento e seleção, e destacou-se este discurso:

É de extrema importância o uso de algum meio de auxílio para o recrutamento de profissionais qualificados, para verificação das informações passadas pelo profissional, assim o contratante tem a confiança e a certeza de estar colocando em sua empresa um profissional qualificado e de qualidade (GRH.1).

Complementou-se tal entendimento com a fala de outro gestor entrevistado: "Enxergo de uma forma mais ampla para obter grandes profissionais, porque podemos ter candidatos qualificados independente do seu local" (GRH.3).

Por sua vez, o GRH.2 compreendeu que a tecnologia poderia impactar de duas formas, conforme se explicita abaixo. 
Primeiramente, os processos de Recursos Humanos estão cada vez mais dinâmicos, com o uso de várias ferramentas para a análise de perfis, pesquisas de clima, avaliações de desempenho entre outras. O segundo ponto é que por consequência, essa informatização dos processos, obriga os profissionais da área, a não só se manterem atualizados quanto à operacionalização destas ferramentas, quanto a criação de novas ferramentas.

Os gestores foram unânimes em assumir o quanto a tecnologia era primordial para se manterem atualizados na área e na busca de profissionais mais qualificados. Tais falas dos entrevistados são reforçadas pelo argumento de Sousa (2014) ao defender que a tecnologia deve oferecer aos gerentes e colaboradores ferramentas e métodos para viabilizar e trabalhar frente as metas e objetivos complexos e mutáveis.

\subsection{CONTRIBUIÇÃO DOS APARATOS TECNOLÓGICOS}

A contribuição dos aparatos tecnológicos colabora para um melhor gerenciamento, trazendo mais rapidez nas comunicações e nas informações. Tornam os processos mais eficientes sendo grandes aliados dos gestores de recursos humanos. Para Senba (2014) os recursos tecnológicos estão sendo utilizados como meio de complementar os processos tradicionais, pois existem aspectos que a tecnologia não pode avaliar em candidatos nos processos de recrutamento e seleção, por exemplo, a assertividade não pode ser analisada por meio das redes sociais.

De acordo com os relatos dos gestores sobre as contribuições dos aparatos tecnológicos no aperfeiçoamento no processo de recrutamento e seleção o GRH.1 comentou que:

\footnotetext{
A contribuição da tecnologia é de extrema importância, pois com ela temos uma pequena seleção antes do contato presencial, assim já temos um aumento de qualidade nos profissionais recrutados e que vão passar pelas entrevistas ou possíveis funcionários.
}

Já o entrevistado GRH.3 relatou que a tecnologia contribuía tanto para o candidato como para a empresa como demonstrou a sua fala: "Contribuem em uma melhor visão tanto para o candidato como para a empresa." 
Por fim, o entrevistado GRH.2 disse que o processo de seleção seria sempre a análise final e que os demais tenderiam a ser feitos de forma sistêmica e que geravam um ganho significativo de tempo como mostrou no discurso a seguir:

O último passo do processo de seleção sempre será a análise do perfil, e na minha opinião, será um processo que se manterá sendo Face-a-Face. Porém, demais processos, como triagens de currículos, aplicação de testes e questionários tendem a ser feitos de forma sistêmicas, que geram um ganho significativo de tempo.

Froehlich e Silva (2014) mencionam que a tecnologia tem se tornado um importante aliado nos processos de RH, auxiliando a identificar profissionais qualificados. Além disso, oferece uma melhor gestão das competências, desenvolvendo, interagindo e aproximando gestores e colaboradores através do alcance das informações úteis para tomada de decisões. Portanto, percebeu-se que quando os aparatos tecnológicos são aplicados no recrutamento e seleção contribuem de maneira significativa para a efetividade de tal política sob responsabilidade da gerência de recursos humanos, trazendo diversas vantagens como maior produtividade $\mathrm{e}$ comprometimento do quadro de pessoal.

\subsection{LIMITAÇÕES DOS APARATOS TECNOLÓGICOS NO PROCESSO DE RECRUTAMENTO E SELEÇÃO}

Os aparatos tecnológicos trazem grandes benefícios ao mundo profissional, mas acabam tendo também algumas limitações em seu uso e importância para a organização, que devem ser bem gerenciadas. A falta do contato pessoal pode acarretar em escolhas não muito assertivas para a organização. Para Abreu et al. (2014), os principais problemas do recrutamento de pessoal via internet é a pouca visibilidade ao divulgar suas vagas e a dificuldade dos candidatos com o acesso à internet. Então, os gestores entrevistados apontaram alguns fatores que a tecnologia limitou no processo de recrutamento e seleção no hotel, cujo entrevistado GRH.1 opinou que o fator que limitava ocorria porque só tinha um único meio de divulgação, que consistia no site.

Nossa tecnologia limita no processo de recrutamento pois o único meio é o site e assim não temos a divulgação para oferecer a vaga, sendo assim ficamos presos apenas a interessados que procuram via web. GRH.1. 
O entrevistado relatou ainda que a tecnologia atrapalhou em seu processo seletivo através da veracidade das informações:

Recentemente tivemos o envio de um currículo com várias recomendações junto com várias qualificações e no contato presencial onde nosso diretor e nossa governança ao realizar a entrevista constataram a mentira nas informações contidas. (GRH.1).

Por sua vez, o entrevistado GRH.2 falou que:

Eu sou entusiasta do uso da Tecnologia nas mais diversas áreas do Hotel, com isso, não vejo como ela pode limitar em algum momento o processo. Devemos apenas ter a devida precaução com a segurança da informação, pois o vazamento de informações confidenciais ou estratégicas pode causar danos severos à organização.

O entrevistado GRH.3 falou que o candidato não podia se expressar tão bem quanto pessoalmente como relatou a seguir: “ Muitas vezes as limitações são criadas porque os candidatos podem não se expressar tão bem quanto pessoalmente".

Observou-se que os gestores não tiveram o mesmo ponto de vista, pois um relatou a falta de mais recursos tecnológicos no processo de recrutamento e seleção e o outro disse que não enxergava como a tecnologia poderia ter limitações quando se tinha a noção de aplicá-la para avanço de técnicas e métodos em processos seletivos, pois deveriam ter apenas cuidados com as informações para não causar danos severos a organização.

\subsection{CONTRIBUIÇÃO DA TECNOLOGIA NO RECRUTAMENTO E SELEÇÃO DO HOTEL}

A contribuição da tecnologia se torna uma ferramenta indispensável no setor de recursos humanos principalmente na área hoteleira, sendo fundamental para o sucesso de uma organização. Segundo Silva, Mafra e Oliveira (2017), o hotel que não acompanhar a evolução tecnológica para oferecer serviços diferenciados aos hóspedes estará em rota de colisão com a modernidade e deixará de ser competitivo no mercado globalizado. 
Quando questionados sobre os fatores que a tecnologia contribuía para o recrutamento e seleção e como a tecnologia ajudou em seu processo seletivo no hotel, foi constatado que:

\begin{abstract}
O único ponto positivo que nossa tecnologia ajudou até o presente momento foi na procura de pessoas que realmente querem ingressar em nossa empresa pois, como a única procura é por nosso site ou e-mail, só vieram pessoas interessadas pela vaga ou que precisam de vaga. Onde nossa tecnologia ajudou foi em ter a demanda de pessoas que realmente necessitam e procuram vagas (GRH.1).
\end{abstract}

Já outro entrevistado expôs que a tecnologia dinamizava uma série de processos, ajudando o hotel a se organizar para um acesso mais rápido das informações como relatou em seu discurso:

Como citei anteriormente, o uso de sistemas de informação, dinamiza uma série de processos. Como exemplo, posso citar o sistema de gestão de talentos. Diariamente, recebemos em todos os hotéis da rede, dezenas de currículos, e logo que estes são recebidos, são cadastrados no sistema, que ficam disponíveis para todos os hotéis, e podem ser acessados rápido, com a aplicação de filtros como Perfil, experiências, Pretensão Salarial, entre outros (GRH.2).

E, por fim, o entrevistado GRH. 3 relatou que a tecnologia ampliava a empresa, podendo estar em qualquer lugar e em qualquer momento como mostrou no discurso abaixo:

A tecnologia amplia o desenvolvimento da empresa, sendo uma empresa que pode estar em qualquer lugar a qualquer momento. Um exemplo é um profissional que se inscreve para um processo seletivo sendo ele muito bem requisitado curricularmente e na data agendada ele está viajando, sendo assim, a tecnologia ajuda a captar esse profissional e tendo a oportunidade de contratá-lo (GRH.3).

Portanto, percebeu-se que a tecnologia era essencial tanto para os gestores como para os candidatos, trazendo mais agilidade, melhoria na comunicação e no recrutamento de novos talentos para a empresa, de acordo com o entendimento de Senba et al. (2014). Contudo, as novas tecnologias vêm revolucionariamente sendo utilizadas pelos departamentos de Recursos Humanos na área de Gestão de Pessoas e por empresas especializadas por buscar novos talentos, implementando-as nos Processos de 
Recrutamento e Seleção de Pessoal. Apresenta-se em seguida um quadro explicitando as categorias e seus devidos significados a partir dos relatos dos entrevistados.

QUADRO 2 - CATEGORIAS E SIGNIFICADOS

\begin{tabular}{|c|c|}
\hline Categorias & Significados \\
\hline $\begin{array}{l}\text { Meios Tecnológicos } \\
\text { Utilizados }\end{array}$ & $\begin{array}{l}\text { As tecnologias utilizadas nos recursos humanos tornaram-se uma } \\
\text { ferramenta essencial para a avaliação de candidatos, a tecnologia é um } \\
\text { aliado chave para a realização de todas as tarefas no hotel em seu processo } \\
\text { seletivo. }\end{array}$ \\
\hline $\begin{array}{l}\text { Perfil Adequado do } \\
\text { Candidato }\end{array}$ & $\begin{array}{l}\text { É preciso ter as características para se preencher a vaga, aquele que se } \\
\text { aproxima mais do perfil esperado para o cargo. }\end{array}$ \\
\hline Divulgação de Vagas & $\begin{array}{l}\text { A divulgação de vagas é de mera importância para a área de recursos } \\
\text { humanos, podendo ser utilizada por diversos meios de divulgação como } \\
\text { anúncios em jornais, fórum em universidade e e-mail, sites e indicação de } \\
\text { colaboradores ou agências. }\end{array}$ \\
\hline $\begin{array}{l}\text { O Impacto Tecnológico } \\
\text { no Mercado }\end{array}$ & $\begin{array}{l}\text { A tecnologia demonstra se relacionar bem com a área de recursos humanos } \\
\text { frente as várias mudanças ocorridas especificamente no processo de } \\
\text { recrutamento e seleção. A tecnologia tem impactado no aumento de } \\
\text { produtividade e na redução do tempo de resposta para a melhoria das } \\
\text { decisões tomadas, alcançando melhor agilidade em suas atividades. }\end{array}$ \\
\hline $\begin{array}{l}\text { Contribuição dos } \\
\text { Aparatos Tecnológicos }\end{array}$ & $\begin{array}{l}\text { Os aparatos tecnológicos contribuem para a facilidade dos processos no } \\
\text { recrutamento e seleção, com rapidez de informações, trazendo redução de } \\
\text { custos, agilidades e inovação para atingir os maiores números de } \\
\text { candidatos. }\end{array}$ \\
\hline $\begin{array}{c}\text { Limitações dos Aparatos } \\
\text { Tecnológicos no Processo } \\
\text { de Recrutamento e } \\
\text { Seleção }\end{array}$ & $\begin{array}{l}\text { Na visão dos gestores o uso da tecnologia no recrutamento e seleção } \\
\text { limitou-se nos poucos meios de divulgação para oferecer vagas aos } \\
\text { candidatos e pela falta da veracidade das informações podendo causar } \\
\text { danos severos na organização. }\end{array}$ \\
\hline $\begin{array}{l}\text { Contribuição da } \\
\text { Tecnologia no } \\
\text { Recrutamento e Seleção } \\
\text { do Hotel }\end{array}$ & $\begin{array}{l}\text { A tecnologia contribui na capacidade de aperfeiçoamento na busca de } \\
\text { novos talentos, ajudando o hotel na execução de suas tarefas contribuindo } \\
\text { para o bom desempenho, encontrando nas mais variadas formas candidatos } \\
\text { que melhor se encaixem nas vagas solicitadas. }\end{array}$ \\
\hline
\end{tabular}
FONTE: Pesquisa de campo (2018).

\section{CONSIDERAÇÕES FINAIS}

A tecnologia vem se tornando fundamental nas diversas políticas de Recursos Humanos, e nesse estudo se buscou focar o recrutamento e seleção, já que é a política desta área que trata da admissão de pessoal, ou seja, é o primeiro contato com o possível funcionário, o que exige qualidade na execução da política para que a contratação seja correta. Assim, a pesquisa objetivou compreender a relação do uso da tecnologia com o processo de recrutamento e seleção de pessoal a partir da visão de três gestores de hotéis da orla de João Pessoa/Paraíba, Brasil. 
Os resultados obtidos trouxeram que o uso da tecnologia nos hotéis foi relevante por tornarem os processos de recrutamento e seleção mais rápidos e confiáveis para a organização, facilitando também a vida de seus candidatos. Na percepção dos gestores, os impactos tecnológicos acarretaram mudanças na realização desta política no ramo hoteleiro, dinamizando o processo seletivo de forma que agilizaria na escolha e assertividade do candidato.

Assim, com relação aos meios tecnológicos utilizados nos hotéis, os gestores entrevistados confirmaram que ocorria através de sites ou e-mail a divulgação de vaga e o contato inicial com os candidatos. No entanto, frisaram que o presencial ainda era importante entre as organizações, uma vez que esta modalidade apresentava o perfil comportamental do candidato. Segundo os gestores, os fatores que a tecnologia limitou era ter um único meio de divulgação para oferecer a vaga, bem como a veracidade das informações colhidas dos candidatos.

Portanto, de maneira geral, a tecnologia se mostrou essencial tanto para os gestores como para os candidatos, pois desempenharia um papel imprescindível nas operações dos hotéis. A utilização das ferramentas tecnológicas é um desafio para os gestores que devem passar por uma nova adaptação para condução do processo de recrutamento e seleção. Nesse sentido, estudos voltados a uma análise mais aprofundada do uso e disseminação da tecnologia nesta e em outras políticas da área de Recursos Humanos podem promover uma melhor compreensão da temática.

Por fim, especificamente em relação ao recrutamento e seleção, constata-se que vem tendo implantação de novas dinâmicas em sua realização e futuras pesquisas podem delinear o domínio dos treinadores e, também, dos candidatos quanto ao ferramental tecnológico utilizado, assim como avaliar se tais tecnologias realmente contribuem para uma escolha mais ágil e acertada por parte da organização.

\section{REFERÊNCIAS}

ABREU, N. R.; BALDANZA, R. F; ATAIDE, J. A. R.; SERQUEIRA, I. F. G. Erecruitment no setor hoteleiro: um estudo na cidade de Maceió. Revista GEINTECGestão, Inovação e Tecnologias, v. 4, n. 5, p. 1292-1309, 2014. 
ARAÚJO, S.; RAMOS, A. Recrutamento on-line: estudo da percepção de utilização da internet em empresa de consultoria de recursos humanos. XXII Encontro Nacional de Engenharia de Produção (ENEGEP), v. 22, 2002.

FERNANDES, D. M. Recrutamento e Seleção de Pessoas: Processo fundamental para a escolha de uma boa equipe profissional. 2011.

FERREIRA, F. S.; VARGAS, E. C. A importância do processo de recrutamento e seleção de pessoas no contexto empresarial. Estação Científica, v. 4, n. 2, p. 21-39, 2014.

FROEHLICH, C.; SILVA, C. T. As contribuições da Tecnologia da Informação nos Processos de Recursos Humanos em uma empresa do segmento calçadista. Diálogo, n. 26, p. 77-96, 2014.

GIL, A. C. Métodos e técnicas de pesquisa social. 6. ed. São Paulo: Atlas, 2008

GODINHO, A. M. E-recruitment-recrutamento e seleção on-line: estudo de caso Catho online. Monografia de Graduação. 36 p. UNICEUB - Centro Universitário de Brasília. Brasília/DF, agosto de 2008.

GOMES, T. C.; SCHERER, L. A.; LÖBLER, M. L. Uso das redes sociais virtuais no processo de recrutamento e seleção de pessoal: uma análise na perspectiva de profissionais de recursos humanos. Anais..., SIMPOI. 2012.

GONTIJO, C. L. Captação e Seleção de talentos para as organizações. Gestão e Conhecimento. Poços de Caldas, v. 2, n. 2, p. 1-14, 2005.

LEMES, A. G.; WESCHENFELDER, G. V. A influência das redes sociais virtuais nos processos de recrutamento e seleção. Gestão Contemporânea: Revista de negócios da Cesuca, [S.1.], v. 2, n. 3, nov. 2015.

LIMA, T. B.; AMARAL, E. V. S. A percepção dos colaboradores de um hotel da capital paraibana sobre a política de recrutamento e seleção. Revista de Turismo Contemporâneo. Natal, v. 6, n. 1. 2018.

LIMONGI-FRANÇA, A. C.; ARELLANO, E. B. Os processos de recrutamento e seleção. In: FLEURY, M. T. L. (Coord.). As pessoas na organização. São Paulo: Ed. Gente, 2002.

MARTINS, S. F. L. A procura online dos talentos: o papel dos sites de redes sociais no recrutamento de candidatos. 2015. Tese de Doutorado. Instituto Superior de Ciências Sociais e Políticas. 2015.

MENDES FILHO, L. A. M.; RAMOS, A. S. M. A Internet como novo paradigma tecnológico e organizacional da gestão hoteleira: uma seleção de serviços e aplicações utilizados pelos hotéis. Revista da FARN. Natal, RN, v. 2, n. 1, p. 11-24, 2002 
MILKOVICH, G. T.; BOUDREAU, J. W. Administração de Recursos Humanos. São Paulo: Atlas, 2000.

MONTENegRO, A. V. Recrutamento e Seleção de Pessoal: Perspectivas e desafios para a gestão estratégica de pessoas. Portal dos Psicólogos. 2012.

MOREIRA, F. G. A importância da Gestão Estratégica no Recrutamento e Seleção de Pessoal nas Organizações. Práticas de Administração Pública, v. 1, n. 2, p. 57-70, 2017.

PÍCCOLO, D. R.; GÂNDARA, J. M. G. Distribuição espacial da hotelaria de rede no estado do Paraná (Brasil). Turismo e Sociedade. Curitiba, v. 5, n. 2, 2012.

PONTES, B. R. Planejamento, recrutamento e seleção de pessoal. 6. ed. São Paulo: LTr, 2010.

SILVA, C. G. Impactos de Programas Nacionais de Turismo sobre as instituições e organizações turísticas em municípios do Pará (Brasil). Turismo e Sociedade. Curitiba, v. 10, n. 3. 2017.

SILVA, L. A. Gestão de Pessoas: o processo de seleção, objetivando as entrevistas como ferramenta organizacional no processo de recrutamento de pessoal nas organizações. Seget, 2015.

SILVA, V.; FERRETT, K.; MANCINI, R. Recrutamento e Seleção: Um estudo sobre as técnicas utilizadas nas organizações. ETIC-ENCONTRO DE INICIAÇÃO CIENTÍFICA-ISSN 21-76-8498, v. 10, n. 10, 2015.

SILVA, A. B. A vivência de conflitos entre a prática gerencial e as relações em família. Tese (Doutorado em Engenharia de Produção). - Universidade Federal de Santa Catarina, Florianópolis, 2005.

SOUSA, S. F. I. Recrutamento e seleção: um dinamismo sazonal. Dissertação de Mestrado. Faculdade de Letras. Universidade do Porto. 114 p. Programa de Ciências Sociais, Portugal, 2014.

Recebido em: 03-08-2018.

Aprovado em: 02-09-2018.

Versão finalizada para publicação em: 28-12-2018. 